\title{
IS THERE A RECREATIONAL MISUSE POTENTIAL FOR PREGABALIN? ANALYSIS OF ANECDOTAL ONLINE REPORTS IN COMPARISON WITH RELATED GABAPENTIN AND CLONAZEPAM DATA
}

\author{
FABRIZIO SCHIFANO ${ }^{1}$, STEFANO D'OFFIZI ${ }^{1,2}$, MICHELE PICCIONE ${ }^{2}$, ORNELLA \\ CORAZZA $^{1,3}$, PAOLO DELUCA ${ }^{3}$, ZOE DAVEY ${ }^{3}$, GIUDITTA DI MELCHIORRE ${ }^{1}$, LUCIA DI \\ FURIA $^{4}$, MAGI' FARRE ${ }^{5}$, LIV FLESLAND ${ }^{6}$, MIIA MANNONEN ${ }^{7}$, AINO MAJAVA ${ }^{7}$, STEFANIA \\ PAGANI ${ }^{4}$, TEUVO PELTONIEMI ${ }^{7}$, HOLGER SIEMANN ${ }^{8}$, ARVID SKUTLE $^{6}$, MARTA \\ TORRENS ${ }^{5}$, CINZIA PEZZOLESI ${ }^{1}$, PEER VAN DER KREEFT ${ }^{9}$, NORBERT SCHERBAUM ${ }^{8}$
}

\footnotetext{
1 'ReDNet' and 'Psychonaut Web Mapping' Projects; University of Hertfordshire School of Pharmacy, Hatfield, UK

${ }^{2}$ Psychiatry and Clinical Psychology Department, Umberto I, "La Sapienza" University of Rome Medical School, Rome, Italy; Viale Regina Elena 244, 00161, Rome,Italy; doffizi.stefano@gmail.com; michele.piccione@uniroma1.it

${ }_{3}$ Psychonaut Web Mapping Project; National Addiction Centre, Institute of Psychiatry, King's College London, London, UK; 4 Windsor Walk; SE5 AF; paolo.deluca@kcl.ac.uk; zoe.davey@kcl.ac.uk

${ }^{4}$ Psychonaut Web Mapping Project; Servizio Salute Regione Marche, Ancona, Italy; Assessorato Salute Regione Marche. Address. Via Gentile da Fabriano 3. Ancona 60100; lucia.difuria@regione.marche.it; stefy.pagani@gmail.com

${ }^{5}$ Psychonaut Web Mapping Project; IAPS-IMIM-Hospital del Mar-UAB, Barcelona, Spain; Passeig Marítim 25-29. Barcelona 08003;

MTorrens@imim.es; Mfarre@imim.es

${ }^{6}$ Psychonaut Web Mapping Project; Bergen Clinics Foundation, Centre of Competence, Bergen, Norway; Vestre Torggate 11 -

5015 Bergen; arvid.skutle@bergenclinics.no; liv.holmefjord.flesland@bergenclinics.no

${ }^{7}$ Psychonaut Web Mapping Project; A-Clinic Foundation, Department of Communications, Helsinki, Finland; Paasivuorenkatu 2A; 00530; Helsinki; teuvo.peltoniemi@a-klinikka.fi; aino.majava@a-klinikka.fi; miia.mannonen@a-klinikka.fi

${ }^{8}$ Psychonaut Web Mapping Project; Addiction Research Group at the Department of Psychiatry and Psychotherapy, LVR-Hospital Essen, Hospital of the University Duisburg-Essen, Germany; Virchowstraße 174. D-45122 Essen; norbert.scherbaum@uni-due.de; holger.siemann@lvr.de

${ }_{9}$ Psychonaut Web Mapping Project; De Sleutel Technische Bedrijfseen heid Provincialaat der Broeders van Liefde, Merelbeke, Jozef Guislainstraat 43 a; B-9000; Gent Belgium; peer.van.der.kreeft@fracarita.org
}

Text: 989 words

\section{Corresponding author:}

Professor Fabrizio Schifano

Chair in Clinical Pharmacology and Therapeutics

Associate Dean, Postgraduate Medical School

Consultant Psychiatrist (Addictions)

University of Hertfordshire

School of Pharmacy

College Lane Campus

Hatfield, Herts

AL10 9AB (UK)

telephone: +44 (0)1707-286107

fax: $+44(0) 1707-284506$

mobile: +44(0)778900 6809

email: F.Schifano@herts.ac.uk 
Background: Although pregabalin abuse potential is reportedly low, online data related to its recreational misuse potential have recently been identified. We aimed here at formally analysing pregabalin misuse web reports and comparing these with data pertaining to similar drugs, e.g. gabapentin and clonazepam, for which an abuse potential has already been identified.

Methods: An 8-language analysis of the online information on pregabalin acquisition/misuse was carried out. An initial sample of 203 websites was considered and 108 relevant websites were monitored on a regular basis. To obtain material relating to gabapentin and clonazepam, an English-language search was carried out and 32 relevant websites were examined.

Results: Misuse of pregabalin, which is commonly offered for sale online, was allegedly associated with sedative and/or psychedelic effects. This was associated with both higher dosages than clinically advised and idiosyncratic (i.e.: IV, rectal, intranasal) drug intake modalities. Although perceived as less powerful than pregabalin, gabapentin misuse was associated with similar sedative/psychedelic effects. Clonazepam allegedly induced either sedation or stimulation, depending on the dosage.

Conclusions: Pregabalin experimenters might be profiled as individuals with a history of recreational polydrug misuse. Pregabalin misuse might be facilitated by easy online accessibility; potency; and peculiar, including anxiolytic, psychoactive effects. Physicians should carefully evaluate patients for history of drug abuse and observe them for signs of pregabalin/gabapentin/clonazepam misuse.

Key words: pregabalin, gabapentin, clonazepam, recreational use, Psychonaut Project, ReDNet project, online pharmacies, Internet monitoring 


\section{Introduction}

With online pharmacies, prescription drugs may be more widely accessible (1-3). In particular, preliminary online information pertaining to both pregabalin purchase availability and its recreational misuse potential has been recently identified (4). Pregabalin is a prescription drug licensed to treat generalized anxiety disorder; partial epilepsy; and neuropathic pain. Since its misuse potential is reportedly low (5-7), we aimed here at formally analysing both pregabalin misuse anecdotal online reports and its online purchase availability levels. Pregabalin data were here compared with related clonazepam and gabapentin online information. In fact, pregabalin is structurally related to gabapentin (8), and shares some therapeutic indications with clonazepam. Interestingly, both clonazepam (9-11) and gabapentin (12-13) possess an identified abuse potential, at least in selected populations.

\section{Materials and methods}

Between January 2008 and August 2010, qualitative Google searches of 203 websites have been carried out in 8 European languages (English, German, Spanish, Italian, Dutch, Norwegian, Finnish, Swedish) using keywords such as 'legal highs'; 'research chemicals'; 'online pharmacy'; 'Lyrica'; 'pregabalin'; and 'online pharmacies'. Out of these, 108 websites were monitored on a regular basis, i.e. daily $(n=21)$, weekly $(n=32)$, monthly $(n=55)$, depending on relevance; the remaining 95 websites were not considered here to be relevant. To obtain material relating to gabapentin and clonazepam, the Google search was carried out in English, with 52 websites examined and 32 identified as relevant. Links from above websites/forums, and other related material were followed as well. The SW London/St George's Ethics Committee granted the study permission.

\section{Results}

Pregabalin was here described as an 'ideal psychotropic drug' for recreational purposes to achieve specific mindsets, including: alcohol/GHB/benzodiazepine-like effects mixed with euphoria; to achieve entactogenic feelings and DXM-like disassociation; and to cope with opiates/opioids' withdrawal (Table 1). A pregabalin vs gabapentin experimentation YouTube video (14) was here identified as well. Misuse of pregabalin mostly seemed to occur orally, but IV; rectal ('plugging'); and 'parachuting' (emptying the content of the capsule into a pouch) self-administration techniques were also reported. Time of onset of the effects ranged here between 10 mins-2hours, depending on the route of administration. Tolerance may reportedly develop fairly rapidly, to wear off quickly after drug cessation.

Similarly, gabapentin seemed to possess both heavy sedative ('..it's like I'm on a fully-sedated opiate buzz....') and psychedelic ('..I feel a disassociation much like DXM...'; '...1200mgs+ has me in an off buzz slightly reminiscent of MDMA....') effects. Interestingly, however, one user argued that 'pregabalin outshines gabapentin. Far less dosage to achieve the same recreational high....'. Similarly to pregabalin, drug tolerance could reportedly develop very rapidly.

Conversely, clonazepam was reportedly inducing either sedation (at 1-2 mg) or stimulation (at more than $8 \mathrm{mg}$ ). Clonazepam was typically co-administered with different sedatives and/or psychedelics. Pregabalin, gabapentin and clonazepam were commonly offered for sale on the web, without the need of a prescription.

\section{Table 1: Summary of online alleged users' accounts of pregabalin, gabapentin and clonazepam misuse}

\begin{tabular}{|c|c|}
\hline $\begin{array}{l}\text { Comments } \\
\text { on dosages } \\
\text { taken and } \\
\text { the } \\
\text { allegedly } \\
\text { achieved } \\
\text { psychoacti } \\
\text { ve effects }\end{array}$ & 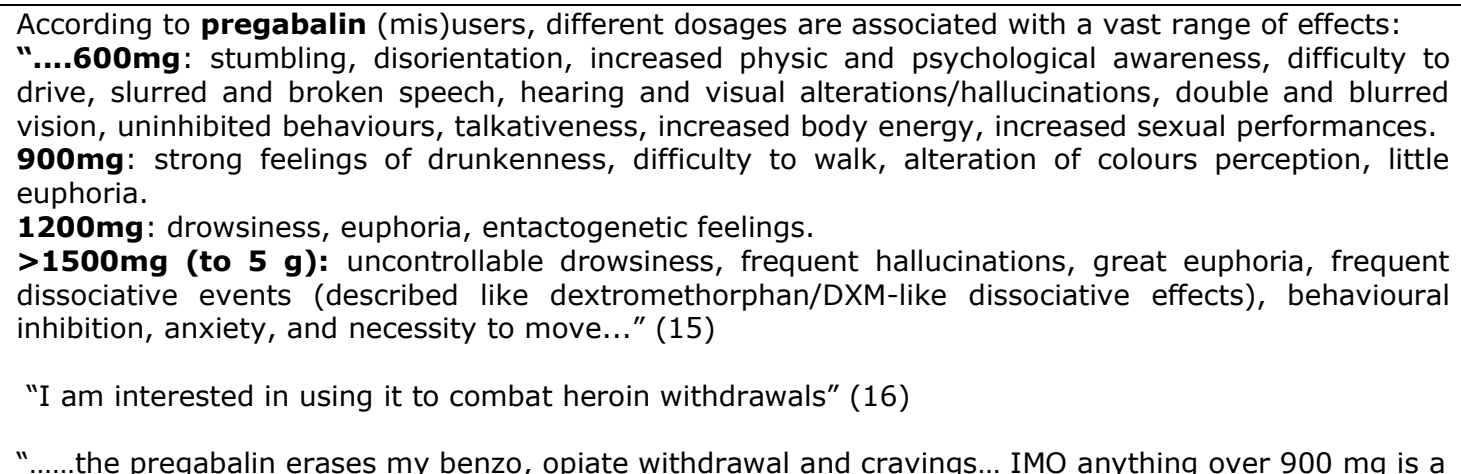 \\
\hline
\end{tabular}




\begin{tabular}{|c|c|}
\hline & 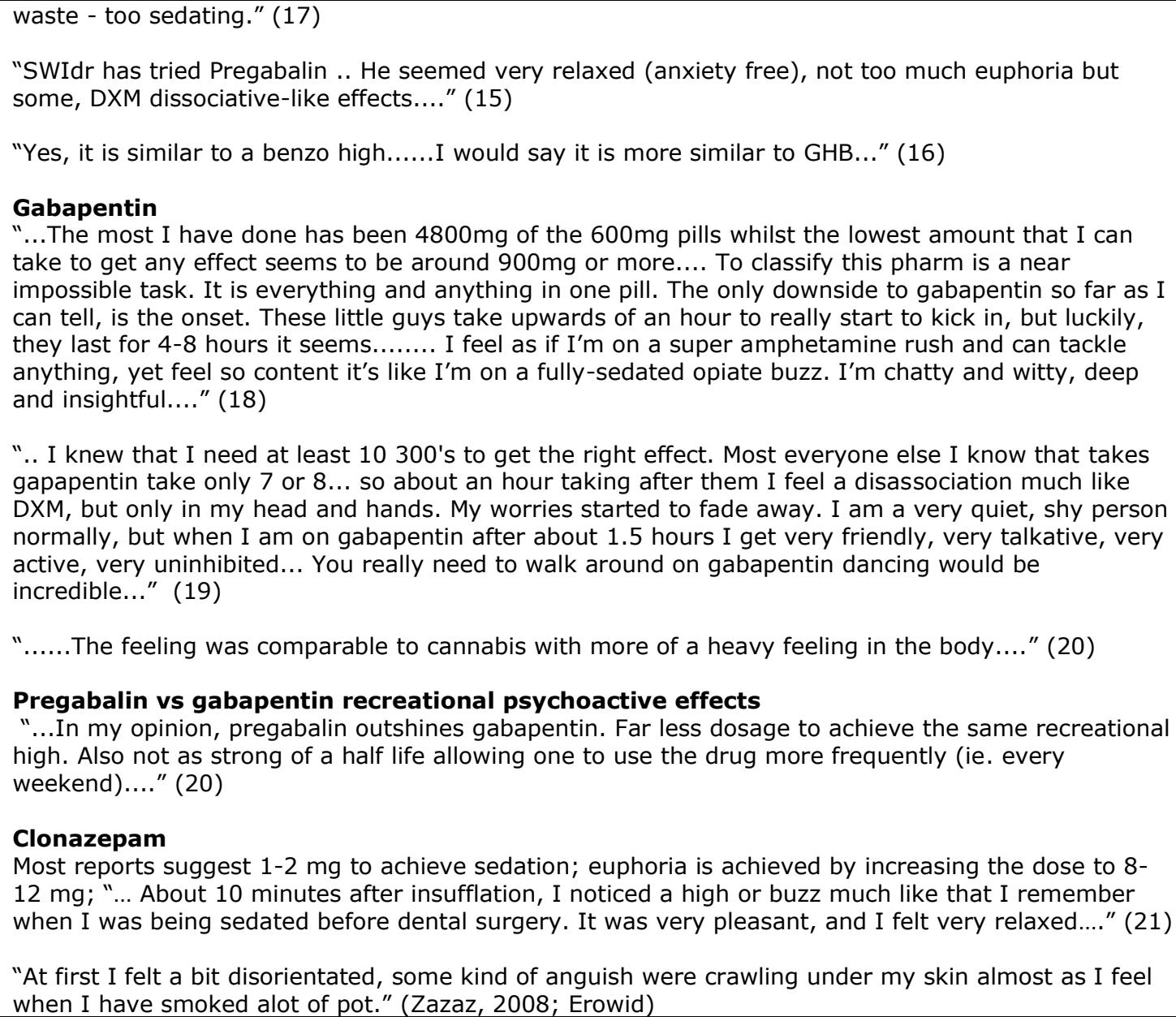 \\
\hline $\begin{array}{l}\text { Different } \\
\text { routes of } \\
\text { administrat } \\
\text { ion }\end{array}$ & $\begin{array}{l}\text { Pregabalin } \\
\text { Intravenous } \\
\text { "When the effects wore off, I decided to shoot one capsule. That was fantastic, I felt so good!! Now I } \\
\text { will only use the lyrica IV. (it is perfect for injection, you empty the capsule in the cup..... you shoot a } \\
\text { very pure solution)" (17) } \\
\text { "I tried injecting it also. Almost all the powder inside the capsule is not water-soluble, but the } \\
\text { pregabalin is very water soluble, so with a big cotton I was able to get a pretty damn clear solution } \\
\text { outta there...." (16). } \\
\text { Rectal/plugging } \\
\text { "SWIM (a 75kg male) ... put the contents of a } 75 \text { mg pregabalin capsule into water, and it didn't } \\
\text { dissolve (which seems odd that pregabalin should be freely water soluble, but maybe more water } \\
\text { would have been needed to dissolve all powder), but SWIM plugged the mixture.....Effects were felt } \\
\text { after } 5 \text { minutes, were very close to the peak at } 10 \text { minutes, and did peak at } 15 \text { minutes. The effects } \\
\text { seemed a bit more relaxing than usual, and it is hard to judge but SWIM would say that it shared a } \\
\text { duration with oral administration and this dosage is equivalent to } 150-300 \text { mg taken orally...." (15). } \\
\text { "Swims used the drug rectally ....notices that its alot more soluble when the cap is opened first and } \\
\text { the powder emptied out but if you dont want to go through the hassle hot water will easily dissolve } \\
\text { the whole capsules. Just let it cool down a little before plugging." (15). } \\
\text { Parachuting } \\
\text { "I just parachuted } 2000 \text { mgs of pregabalin powder. In two hours I'll see how f....d up I am. I have } \\
\text { huge tolerance though..." (17) } \\
\text { Gabapentin: oral; intramuscular } \\
\text { Clonazepam: oral; crushed and eaten; snorting (grinding up the tablet and snort the mixture); } \\
\text { intramuscular }\end{array}$ \\
\hline Tolerance & $\begin{array}{l}\text { Pregabalin } \\
\text { "Lyrica has an extremely high ceiling. I'm not suggesting you do } 600+\text { mg your first time, but I have } \\
\text { taken amounts } 3000+\mathrm{mgs}[\ldots] \text { with Lyrica you gain tolerance extremely quickly." (17). } \\
\text { Gabapentin } \\
\text { "..The most troubling thing about gapabentin was the tolerance level was very high. Each successive }\end{array}$ \\
\hline
\end{tabular}




\begin{tabular}{|c|c|}
\hline & $\begin{array}{l}\text { dosing required more and more to achieve the same level. Doing gabapentin two days in a row was } \\
\text { impossible...." (20) } \\
\text { Clonazepam } \\
\text { "...The benzo (clonazepam) created a very creative and almost 'giddy' type of reaction similar to } \\
\text { most other benzodiazepines, except this time at a much lower dose and on a much more enjoyable } \\
\text { level (especially considering my tollerance)..." (21) }\end{array}$ \\
\hline $\begin{array}{l}\text { Use in } \\
\text { combinatio } \\
\text { n with } \\
\text { other } \\
\text { substances }\end{array}$ & $\begin{array}{l}\text { Pregabalin is reportedly often taken in combination with other compounds in order to potentiate } \\
\text { their effects, such as (4): } \\
\text { - Alcohol } \\
\text { - Prescribing drugs: benzodiazepines; zopiclone; gabapentin } \\
\text { - Ilicit/recreational drugs: hashish/marijuana; heroin/opiates; amphetamines; LSD. } \\
\text { Gabapentin: } \\
\text { "...I love Gabapentin especially with Baclofen. } 600-900 \text { mgs gives me a nice happy feeling, 1200mgs+ } \\
\text { has me in an off buzz slightly reminiscent of MDMA..." (23). Other drugs reportedly taken in } \\
\text { combination with gabapentin include: cannabis; alcohol; SSRIs; LSD; amphetamine; GHB. } \\
\text { Clonazepam: } \\
\text { Psychoactive drugs reportedly taken in combination include: mushrooms; MDMA; 2C-T-2; cannabis; } \\
\text { nitrous oxide (24); alcohol; morning glory seeds (25) }\end{array}$ \\
\hline $\begin{array}{l}\text { Illustrative } \\
\text { examples } \\
\text { of websites } \\
\text { allegedly } \\
\text { offering } \\
\text { pregabalin } \\
\text { /gabapenti } \\
\text { n/clonazep } \\
\text { am for } \\
\text { purchase } \\
\text { (as of } \\
\text { August } \\
2010 \text { ) }\end{array}$ & $\begin{array}{l}\text { Pregabalin } \\
\text { http://www.drugshoponline.com } \\
\text { http://www.medrex-one.com } \\
\text { http://www.ipharmacylist.com } \\
\text { https://www.israelpharm.com } \\
\text { http://www.canadadrugsonline.com } \\
\text { http://www.medsupport.org } \\
\text { http://www.eurodrugstore.eu } \\
\text { http://www.easy.md } \\
\text { Gabapentin } \\
\text { http://www.pharmacyescrow.com/s4515-s-NEURONTIN.aspx } \\
\text { http://www.77canadapharmacy.com/gabapentin.php } \\
\text { http://www.omfgg.com/profiles/blogs/order-gabapentin-online-order } \\
\text { http://firsthealthstore.net/products/neurontin.htm } \\
\text { Clonazepam } \\
\text { http://www.generictab.com } \\
\text { http://www.buy-clonazepam.com } \\
\text { http://www.coryholt.com } \\
\text { http://www.elegantinteriorsanddesign.com }\end{array}$ \\
\hline
\end{tabular}

Legenda: IMO: in my opinion; SWIM: somebody who is not me; DXM: dextromethorphan. Please note that although spelling mistakes have not been edited, rude words have been deleted. Most data collected from online forums that could be seen as personal identifiable (e.g. usernames, complete URLs for specific threads etc) were here appropriately anonymised.

\section{Discussion and Conclusions}

Pregabalin experimenters might be profiled here as individuals with a history of recreational polydrug misuse $(14 ; 26)$. Pregabalin dosages most typically reported were clearly in excess (e.g. up to $5 \mathrm{~g}$ ) of the maximum level (e.g. $600 \mathrm{mg} ; 27-28$ ) which is clinically advisable. If pregabalin is perceived by misusers to be a valid substitute for most common illicit sedative drugs, this may be a reason for concern.

One could wonder about the anxiolytic properties of pregabalin, gabapentin and clonazepam as potential mediators for misuse. In fact, some users might start self administering with these GABA-ergic drugs as a way of self medicating. Because of rapid development of high tolerance levels with both pregabalin and gabapentin, then increasing dosages are self-administered. Consistently with this self medication hypothesis, some users advised either on the concurrent administration of pregabalin with gabapentin, or on their association with other sedatives, such as alcohol, benzodiazepines and zopiclone.

In line with observations here presented, pregabalin is indeed characterized by higher ( 2.5 times; 29) potency; quicker absorption rates and greater bioavailability levels than gabapentin (30). One could wonder why both gabapentin and pregabalin, in apparent contrast with clonazepam, seem to possess both a sedative and a dissociative effect as well. Although all three compounds are GABA-ergic, pregabalin (31) and gabapentin $(8 ; 32)$ precise mechanism of action is still unclear. Conversely, clonazepam is a well characterized, powerful compound 
which seem to have replaced flunitrazepam as the most popular misusing benzodiazepine (10). A better clarification of the pregabalin misuse potential level is of interest, since the drug has recently been proposed as a treatment for substance misuse, namely for both alcohol (33) and benzodiazepine dependent (34) individuals. Pregabalin potential of misuse is not typically mentioned in the prescribers' aides (e.g. 27; 35). However, controlled clinical studies carried out in over 5500 patients have shown that in some patient populations self-reporting rates of euphoria ranged between 1 and 12\% (29). Abrupt/rapid discontinuation of pregabalin may be associated with insomnia, nausea, headache, or diarrhoea, which may be suggestive of physical dependence (36-37).

One could wonder about the limitations of carrying out a risk of misuse assessment of a drug whilst taking into account the online comments only. In fact, it may be inappropriate to trust information obtained from the internet without independent verification. In April 2010, however, pregabalin has been included in the list of new recreational psychoactive substances officially notified to the relevant EU agencies (38). These concerns have recently been confirmed through analysis of the adverse drug reactions' Swedish national register data (39). Finally, pregabalin is a controlled substance under Schedule V of the United States' Controlled Substances Act.

One could think that only large scale, adequately controlled, clinical studies can give a clear indication of drug characteristics and adverse effects. However, in line with present observations, previous studies from our group (40-41) have clearly suggested that increase in online trafficking/debate about a specific psychoactive drug typically precedes the occurrence of clinical incidents at the population level. As with any centrally active drug, physicians should carefully evaluate patients for history of drug abuse and observe them for signs of anticonvulsants', including pregabalin, misuse $(37 ; 42)$.

\section{Acknowledgments}

The present study was carried out with the support of the European Commission (EC); e.g. for both the Psychonaut Web Mapping System (A/800102; 2006 348) and the ReDNet (EC Executive Agency for Health and Consumers in the framework of the Public Health Programme; 200912 26) projects. The views expressed here reflect only the authors' views and not necessarily those of the relevant EC officers.

No conflicts of interest are declared here which may have influenced the interpretation of present data.

\section{References}

1.Littlejohn C, Baldacchino A, Schifano F, Deluca P: Internet pharmacies and online prescription drug sales: A cross-sectional study. Drugs Educ Prev Policy 2005; 12:75-80.

2. Schifano F, Leoni M, Martinotti G, Rawaf S, Rovetto F: Importance of cyberspace for the assessment of the drug abuse market: preliminary results from the Psychonaut 2002 Project. CyberPsychol Behavior 2003; 6:405-410.

3. Schifano F, Deluca $P$, Baldacchino A, Peltoniemi T, Scherbaum N, Torrens M, Farre M, Flores I, Rossi M, Eastwood D, Guionnet C, Rawaf S, Agosti L, Di Furia L, Brigada R, Majava A, Siemann H, Leoni M, Tomasin A, Rovetto F, Ghodse AH, on behalf of the Psychonaut 2002 research group: Drugs on the web; the Psychonaut 2002 EU project. Progr Neuropsychopharmacol Biol Psychiatry 2006; 30:640-646.

4. Psychonaut Web Mapping Research Group (2009). Lyrica Report. Institute of Psychiatry, King's College London, London, UK. Available from: www.psychonautproject.eu (accessed on February 5, 2010)

5. Bandelow B, Wedekind D, Leon T. Pregabalin for the treatment of generalized anxiety disorder: a novel pharmacologic intervention. Expert Rev Neurother 2007; 7: 769-781. 
6. Chalabianloo F, Schjøtt J: Pregabalin and its potential for abuse. Tidsskr norsk legefor 2007; 129:186-187.

7. European Medicines Agency [EMA] (2006) Scientific Discussion. Available from: http://www.emea.europa.eu/humandocs/PDFs/EPAR/lyrica/Lyrica H-546-II-04-AR.pdf. (accessed on April 15, 2009)

8. Baillie JK, Power I: The mechanism of action of gabapentin in neuropathic pain". Curr Opinion Invest Drugs (London) 2006; 7:33-39.

9. Frauger E, Pauly V, Thirion X, Natali F, Pradel V, Reggio P, Rouby F, Coudert H, Micallef J: Estimation of clonazepam abuse liability: a new method using a reimbursed drug database. Int Clin Psychopharmacol 2009; 24:318-324.

10. Modelon H, Frauger E, Laurenceau D, Thirion X, Mallaret M, Micallef J, ŕeseau des CEIP: Psychotropic drug addiction: consumption study of specific population by the survey OPPIDUM 2004 from the CEIP network. Therapie 2007; 62:337-346.

11. Pradel V, Delga C, Rouby F, Micallef J, Lapeyre-Mestre M: Assessment of abuse potential of benzodiazepines from a prescription database using 'doctor shopping' as an indicator. CNS Drugs 2010; 24:611-620.

12. Mondón S, Nogué S, Urbano D, Rovira E: Gabapentin abuse. Med Clin (Barc) 2010; 134:138-139.

13. Reccoppa L, Malcolm R, Ware M: Gabapentin abuse in inmates with prior history of cocaine dependence. Am J Addict 2004; 13:321-323.

14. You Tube (2010) Neurontin vs Iyrica - pregabalin vs gabapentin. Available from: http://www.youtube.com/watch?v=47nXI7GHVCM (accessed on February 4, 2010)

15. Drugs-forum (2007-2009). Available from: http://www.drugs-forum.com/index.php (accessed on February 4, 2009)

16. Opiophile (2009). Lyrica recreational dosage/IV use. Available from:

http://forum.opiophile.org (accessed on April 15, 2009)

17. BluelightForum (2005-2009) Available from: http://www.bluelight.ru (accessed on April 1, 2009)

18. Azlecs, 2008. Available from:

http://webcache.googleusercontent.com/search?q=cache:wA3RrrGYssAJ:www.erowid.org/exp eriences/exp.php\%3FID\%3D70987+gabapentin+site:erowid.org\&hl=en\&gl=uk\&strip=1

(accessed on July 28, 2010)

19. Valhallen, 2003. Available from: http://www.erowid.org/experiences/exp.php?ID=28984 (accessed on August $2^{\text {nd }}, 2010$ )

20. TheMacGrizzy, 2010. Available from:

http://webcache.googleusercontent.com/search?q=cache:wcw3NLAEQfw]:www.erowid.org/ex periences/exp.php\%3FID\%3D83121+gabapentin+site:erowid.org\&hl=en\&gl=uk\&strip =1

(accessed on July 28, 2010)

21. Stever, 2010. Available from: http://aciddata.com/experiences/exp.php?ID=60394 (accessed on August 2nd, 2010)

22. Zazaz, 2008. Available from:

http://www.erowid.org/experiences/exp.php?ID $=36766$ (accessed on August $2^{\text {nd }}, 2010$ ) 
23. ZzZzZ, 2009. Available from:

http://www.bluelight.ru/vb/showthread.php?t=377305\&page $=2$ (accessed on August $2^{\text {nd }}$, 2010)

24. Phantom, 2010. Taken from:

http://webcache.googleusercontent.com/search?q=cache:ABDdPpaYuS8J: www.erowid.org/exp eriences/exp.php\%3FID\%3D84711+clonazepam\%2Bsite:erowid.org\&hl=en\&gl=uk\&strip=1 (accessed on July 28, 2010)

25. Non Servatum, 2009. Available from:

http://webcache.googleusercontent.com/search?q=cache:vq0ZXX8yiBIJ:www.erowid.org/expe riences/exp.php\%3FID\%3D69766+clonazepam\%2Bsite:erowid.org\&hl=en\&gl=uk\&strip =1 (accessed on July 28, 2010)

26. Fuckled (2009). Available from: http://www.fuckled.co.uk (accessed on March 11, 2009)

27. British National Formulary (BNF) 58. Accessible from:

http://bnf.org/bnf/bnf/58/129078.htm?q=\%22pregabalin\%22 (accessed on December $15^{\text {th }}$ 2009)

28. Pfizer for professionals, 2010. Available from:

https://www.pfizerpro.com/Sites/PFP/pages/product_info/lyrica_pi_dependence.aspx (accessed on January 21st, 2010)

29. Wesche $D$, Bockbrader $\mathrm{H}$. A pharmacokinetic comparison of pregabalin and gabapentin. http://www.ampainsoc.org/abstract/2005/data/684/index.html (accessed on July 31, 2010)

30. McAuley, 2005. How does pregabalin compare to gabapentin in the treatment of neuropathic pain? Available from: http://www.globalrph.com/pregabalin.htm (accessed on July 30th, 2010)

31. Nymdelger S, Nieberg K: Pregabalin: a neuromodulator for the treatment of neuropathic pain, generalized anxiety disorders and cystic fibrosis syndrome. Medizin Monatssch Pharmazeuten 2007; 30:396-400.

32. Hendrich J, Van Minh AT, Heblich F: Pharmacological disruption of calcium channel trafficking by the alpha2delta ligand gabapentin. Proc Natl Acad Sci USA 2008; 105:36283633.

33. Martinotti G, Di Nicola M, Tedeschi D, Mazza M, Janiri L, Bria P:Efficacy and safety of pregabalin in alcohol dependence. Adv Ther 2008; 25: 608-618.

34. Oulis P, Konstantakopoulos G, Kouzoupis AV, Masdrakis VG, Karakatsanis NA, Karapoulios $\mathrm{E}$, Kontoangelos KA, Papadimitriou GN: Pregabalin in the discontinuation of long-term benzodiazepines' use. Hum Psychopharmacol 2008; 23:337-340.

35. Media Pfizer (2010). Lyrica Full Prescribing Information. Available from:

http://media.pfizer.com/files/products/uspi_lyrica.pdf (accessed on January 21st, 2010)

36. Centerwatch (2009) Available from: http://www.centerwatch.com/drug-information/fdaapprovals/drug-details.aspx?DrugID=900 (accessed on December 15, 2009).

37. McEvoy GK: American Hospital Formulary Service. AHFS Drug Information. American Society of Health-System Pharmacists, Bethesda, MD, 2007.

38. EMCDDA-Europol 2009 Annual Report on the implementation of Council Decision 2005/387/JHA; Annex 2 - New psychoactive substances reported to the EMCDDA and Europol 
for the first time in 2009 under the terms of Council (available from:

http://www.emcdda.europa.eu/html.cfm/index33227EN.html; accessed on 22/05/2010)

39. Schwan S, Sundström A, Stjernberg E, Hallberg E, Hallberg P: A signal for an abuse liability for pregabalin-results from the Swedish spontaneous adverse drug reaction reporting system. Eur J Clin Pharmacol 2010; Jun 19. [Epub ahead of print]

40. Schifano F, Corazza O, Deluca P, Davey Z, Di Furia L, Farre M, Flesland L, Mannonen M, Pagani S, Peltoniemi T, Pezzolesi C, Scherbaum N, Siemann H, Skutle A, Torrens M, van der Kreeft P: Psychoactive drug or mystical incense? Overview of the online available information on Spice products. Int J Culture Ment Health 2009; 2:137-144.

41. Siemann H, Specka M, Schifano F, Deluca P, Scherbaum N: Salvia divinorum - Präsenz einer neuen Droge im Internet (Salvia divinorum on the web). Gesundheitswesen 2006; 68:323-327.

42. Grosshans M, Mutschler J, Hermann D, Klein O, Dressing H, Kiefer F, Mann K: Pregabalin abuse, dependence, and withdrawal: a case report. Am J Psychiatry 2010; 167:869. 